\title{
A Stich in Time Saves Nine: Primary Closure in Facial Dog Bite Injuries - A Case Series
}

\author{
Gopinath. A. L ${ }^{1}$, Reyazulla. M. A ${ }^{1}$, Ajay Kumar. ${ }^{1, * *}$, Sushi kadanakuppe ${ }^{2}$ \\ ${ }^{1}$ Department of Oral and Maxillo Facial Surgery, V. S. Dental College and Hospital, Bangalore, India \\ ${ }^{2}$ Department of Preventive and Community Dentistry, V. S. Dental College and Hospital, Bangalore, India
}

Copyright (C) 2015 Horizon Research Publishing All rights reserved.

\begin{abstract}
The purpose of this article is to present a case series of facial dog bites injuries, its management and emphasize the importance of primary closure. Animal bite injuries, unlike wounds caused by assaults and accidents, are more distinctive, as they cause deep puncture wounds. Such wounds are inoculated with pathogenic bacteria from the saliva of the attacking dog due to the penetration of tissue by excessive bite force. Hence, these wounds are at a high risk of infection. The key point in its management is thorough cleansing, meticulous but not overzealous debridement, followed by rabies immunization, tetanus immunization, primary closure, and appropriate antibiotic therapy. A retrospective study of 27 cases that underwent primary repair or reconstruction after wound toilet, debridement and administration of prophylactic antibiotics has been presented.
\end{abstract}

Keywords Dog Bite, Primary Closure, Wound, Face

\section{Introduction}

According to the WHO, ten million people are bitten by animals around the world annually, of which 55,000 people are infected with rabies. Bite wounds are always considered as complex injuries contaminated with unique polymicrobial inoculum. According to an animal bite survey conducted by the WHO in 2004 on Indian population, a majority (75\%) of the animal bite victims belonged to the low income strata. The major causative animal was the dog in $91.5 \%$ of the cases, of which $62.9 \%$ were strays and $37.1 \%$ pets. ${ }^{1}$ In decreasing order of frequency, the locations involved were cervicofacial, lower extremity, upper extremity and the chest. ${ }^{2}$ Interestingly, majority of the dog bite injuries in children occur in the head and neck region, while only $10 \%$ of adults suffer from similar injuries. This significant difference is attributed to the short stature of children, which makes them more vulnerable to facial injuries. The lips, nose and cheek comprise the central target areas.
Force delivered by a dog's bite can be as high as $450 \mathrm{lbs} / \mathrm{sq}$ inch. ${ }^{3}$ Such high quantum of forces delivered by the sharp teeth of these mammals can result in three main types of soft tissue wounds : 1.Punctures, 2.Lacerations and 3. Avulsions with or without actual tissue defect. A typical dog bite results in a combination of puncture -type wounds with adjacent tearing of tissue, which is called as the 'Hole and Tear' effect. ${ }^{3}$ Some degree of crush injury also occurs due to the dynamics of the bite. The clinical implication of puncture wounds is that, due to the presence of a narrow point of entry, poor drainage and inoculation of microorganisms to the deeper tissue planes, it creates an environment ideal for proliferation of anaerobic bacteria. Crush injuries on the other hand, present with superficial wounds and precipitate infection with lower bacterial counts. Apart from the management of esthetics and infection, facial dog bite wounds can be especially challenging when there are concomitant injuries to the vital structures like airway, the cervical spine, surrounding vascular structures, intracranial, ocular structures, the facial nerve and the parotid duct.

\section{Patients and Methods}

All the patients with facial dog bite injuries who had presented to The Department of Oral and Maxillofacial Surgery with dog bite injuries to the face from January 2013 to January 2014 were treated with primary closure and followed up for a period of 6 months. The positive and negative outcomes of primary repair and reconstruction were studied.

A total of twenty seven patients with ages ranging from 1-52 years had been treated. Twenty six of the patients had presented within 24 hours of injury and one patient arrived 35 hours after the bite. All the patients had been treated within 48 hours of reporting to the hospital. Five patients were operated on, under General Anesthesia and twenty two patients under Local Anesthesia. Twenty six had undergone primary repair and 1 had been treated with a distant flap. The demographic characteristics of patients with dog bite injuries 
are given in Table 1 . The sites of the injury were varied, with the lips, cheeks and nose being the most commonly affected. None of the patients presented with injuries to the adjacent vital structures. The patients were categorized into various types based on the following classification given in Table 2 and Figure 1.

Table 1. The Demographic Characteristics Of Patients.

\begin{tabular}{|c|c|c|}
\hline AGE & DESCRIPTION & $\begin{array}{c}\text { NUMBER OF } \\
\text { PATIENTS }\end{array}$ \\
\hline UPTO 28 DAYS & NEONATE & 0 \\
\hline TILL 1 YEAR & INFANCY & $\mathbf{1}$ \\
\hline 1-3 YEARS & TODDLER & 4 \\
\hline 3-6 YEARS & PRE-SCHOOL & 4 \\
\hline 6-10YEARS & SCHOOL GOING & 11 \\
\hline 14- 18 YEARS & TEENAGERS & 2 \\
\hline >18YEARS & ADULTS & 5 \\
\hline
\end{tabular}

Table 2. The Percentage Of Patients According To Classification Of Facial Bite Injuries. ${ }^{3,4}$

\begin{tabular}{|c|c|c|c|}
\hline Type & $\begin{array}{c}\text { No of } \\
\text { patients }\end{array}$ & $\begin{array}{c}\text { Percentage } \\
\text { of patients }\end{array}$ & Clinical Findings \\
\hline I & 10 & $37.03 \%$ & $\begin{array}{c}\text { Superficial injury without muscle } \\
\text { involvement }\end{array}$ \\
\hline IIA & 14 & $51.85 \%$ & $\begin{array}{c}\text { Deep injury with muscle } \\
\text { involvement }\end{array}$ \\
\hline IIB & 02 & $7.40 \%$ & $\begin{array}{c}\text { Full-thickness injury of the cheek } \\
\text { or lip with oral mucosal } \\
\text { involvement } \\
\text { through-and-through wound) }\end{array}$ \\
\hline IIIA & 01 & $3.70 \%$ & $\begin{array}{c}\text { Deep injury with tissue defect } \\
\text { (complete avulsion) }\end{array}$ \\
\hline IIIB & 0 & 0 & $\begin{array}{c}\text { Deep avulsive injury exposing } \\
\text { nasal or auricular cartilage }\end{array}$ \\
\hline IVA & 0 & 0 & $\begin{array}{c}\text { Deep injury with severed facial } \\
\text { nerve and/or parotid duct }\end{array}$ \\
\hline IVB & 0 & 0 & $\begin{array}{c}\text { Deep injury with concomitant } \\
\text { bone fracture }\end{array}$ \\
\hline
\end{tabular}

All patients had been initially managed with a thorough wound toilet of saline and betadine followed by a surgical debridement of crushed wound edges. Primary closure was then attempted. In patients with substantial tissue loss, reconstruction was performed with local flaps, mucosal advancement, split skin grafts or full thickness grafts. For patients operated under general anesthesia, the hospital stays ranged from 1 to 3 days. After discharge, the patients were followed up on an outpatient basis.

\subsection{Operative Procedures:}

The steps followed in the management of the injuries included:

- $\quad$ Skin preparation and anesthesia

- Proper surgical toilet of the wound by irrigation.

- Meticulous but not overzealous debridement of devitalized tissue [Resection of skin tags, Removal of visible foreign particles]

- Primary closure of the wound except in the high risk cases.
- Appropriate antibiotic therapy.

- Tetanus and rabies immunization.

- Follow-up.

On arrival, all the patients were subjected to general examination by a pediatrician/physician depending on age of patient. vitals (pulse. temperature, respiratory rate, blood pressure) were recorded, examination for other associated injuries was carried out.

All patients were treated with anti-rabies immunoglobulins (human rabies immunoglobulins) into and around the wound. Dosage of immunoglobulins was based on the weight of the patient ( $20 \mathrm{i}$.u per kg body weight). Intra muscular tetanus toxoid of $0.5 \mathrm{ml}$ was given to all patients taking into consideration the age and immunization status. Test dose of $2 \%$ lignocaine was given to all patients, none of the patients presented with adverse reaction towards immunoglobulins, lignocaine.

\section{Surgical toilet of the wound}

Wounds and the surrounding areas were inspected, scrubbed with soap solution, savlon (cetrimide $0.6 \% \mathrm{w} / \mathrm{v}+$ chlorhexidine gluconate solution $0.3 \% \mathrm{v} / \mathrm{v}+$ absolute alcohol $3 \% \mathrm{v} / \mathrm{v}$ ) following which the region was mopped with $0.9 \%$ normal saline. The areas around the wounds were anesthetized with either nerve blocks or infiltration with $2 \%$ lignocaine $+1: 80,000$ adrenaline (adrenaline was mainly used for its local vasoconstriction effect and prolonged duration of action), after completely anesthetizing the area the wound was explored to remove all visible foreign objects. A manual irrigation with $150-200 \mathrm{ml}$ of $0.9 \%$ normal saline was carried out with $10-20 \mathrm{ml}$ syringe an 18-20 gauge needle. The total cleaning time ranged from 10 to 15 minutes. This was followed by careful rinsing with $10 \%$ povidone iodine, diluted with $0.9 \%$ normal saline. All the devitalized tissues and tissue tags were carefully excised keeping in mind not to excessively trim the tissues, as facial tissues have rich vascularity and can survive on small pedicle.

Out of 27 patients 10 patients had bite marks and scratches over the chest, upper extremities, and lower extremities. Even these associated wounds were subjected to wound toilet with irrigation.

\section{Closure}

The wounds were sutured in layers, using resorbable multifilament/monofilament (3-0, 4-0) for deeper layers and non resorbable suture material for epidermis (4-0,5-0). Skin sutures were retrieved after 5-7 days, according to wound healing condition.

All patients received antibiotic coverage of amoxicillin +/clavulanic acid and metronidazole for duration of 3-5 days. None of the patients reported with allergies to the medications.

Five of our patients were operated under general anesthesia. All the patients were less than 7 years of age. The anesthetic agent used was sevoflurane for induction and maintenance. It was administered as a mixture with nitrous oxide and oxygen. For induction inhalation anesthesia 
ranged from 5- 7\% and for maintenance 2- $2.6 \%$ of sevoflurane, in $60 \%$ of nitrous oxide and $40 \%$ of oxygen. The dosage was calculated based on patients weight, and clinical status.

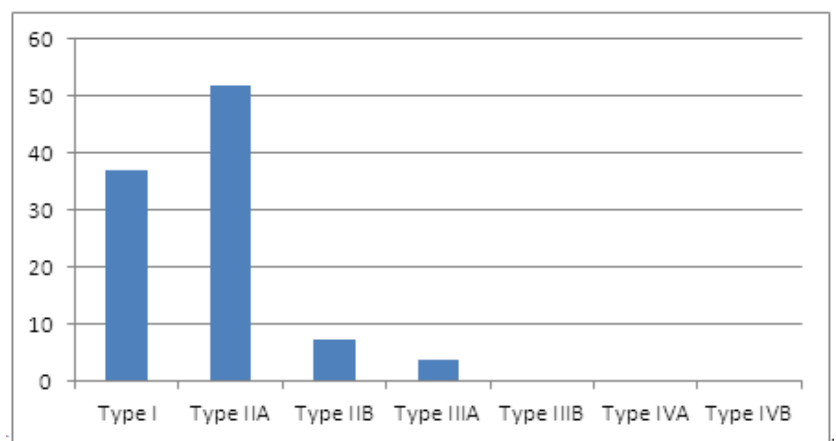

Figure 1. Percentage of the Patients According To Classification Of Facial Dog Bite Injuries.

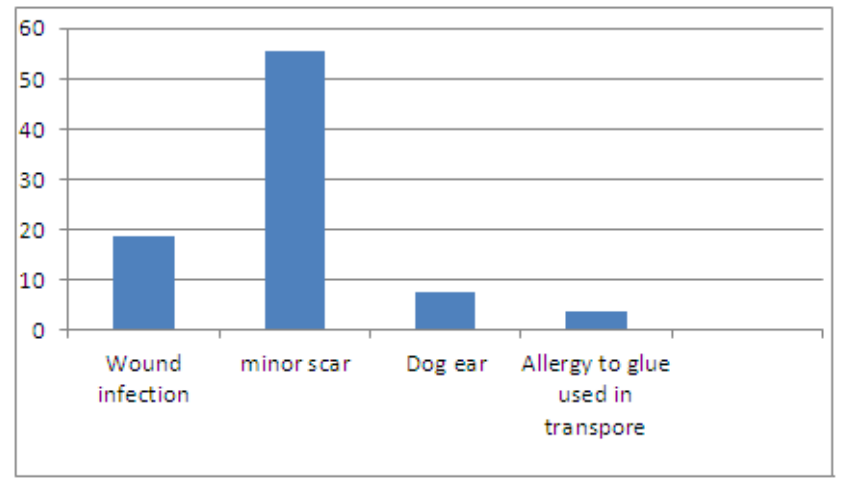

Figure 2. Percentage of patients associated with complications following primary closure.

Following primary closure of facial injuries the following complications were seen, Wound infection were seen in 5 patients (18.51\%), Minor scarring in 15patients $(55.55 \%)$, dog ear deformity in 2patients (7.4\%) and a rare case of allergy to the glue used in transpore was seen in a patient (3.7\%), Figure.2.

\subsection{Complications}

A follow up of the patients extended for four months to one year, during which only minor scarring was seen (Fig.5c).

\section{Discussion}

A thorough history and clinical examination should be conducted to rule out injuries to the associated vital structures in the vicinity. Following the primary assessment, the bite wounds should be assessed for the presence of infection and classified based on the type, size and depth. In this study the patients had been classified as mentioned in Table.1. As with any laceration, the mainstay of wound care is irrigation and removal of any necrotic tissue. ${ }^{3,6,7}$ However, common practices, such as cleaning with soap or scrubbing, are best reserved for high-risk wounds. Irrigation is essential in preventing infection because it removes debris and microorganisms. Puncture wounds are difficult to irrigate thoroughly and hence are twice as likely to become infected. ${ }^{3,8}$

All the patients who had presented to us had undergone a thorough irrigation as mentioned earlier, It was noted that three of the patients had presented with puncture wounds. Care was taken not to incise the puncture wounds as it would lead to unnecessary scaring. A review of literature has shown that manual irrigation of 150 to $500 \mathrm{~mL}$ of solution provides an adequate cleansing effect for most facial bite wounds with a 19-gauge catheter on a 30 - to $60-\mathrm{mL}$ syringe delivers a pressure range between 5 and 8 psi is considered optimal for appropriate decontamination., ${ }^{3,9}$ However, sustained high-pressure irrigation should be avoided in areas containing loose areolar tissue, such as the eyelids or children's cheeks, because such irrigation may cause tissue disruption and excessive edema. ${ }^{3}$ Incising the puncture to promote irrigation is not recommended as it causes unnecessary scarring. ${ }^{3,10}$ Normal saline is the fluid of choice for irrigation. $1 \%$ povidone-iodine solution has also been recommended for irrigation of bite wounds because this solution provides an optimal therapeutic balance between bactericidal capacity and tissue toxicity associated with iodine-containing formulations. However, when used under pressure for wound decontamination, saline has compared favorably with $1 \%$ povidone-iodine solution and other less commonly used alternatives. Moreover, even if povidone-iodine or other antiseptic solutions are used as irrigant, copious rinsing with normal saline should follow to minimize the risk of cytotoxicity. ${ }^{3}$ Debridement of facial wounds should be kept to a minimum so as to avoid sacrifice of tissue that has a good chance to survive, particularly in landmark areas such as the vermilion border of the lips, the nasolabial fold, and the eyebrows.

For uncomplicated bite wounds presenting beyond the "golden 24-hour period" primary closure remains controversial. In these cases, delayed closure is a time-honored practice. ${ }^{3,11,12}$ This implies a waiting period of 4 to 5 days before definitive wound closure, during which the wound is kept open, usually with moist gauze dressings providing drainage, while edema is allowed to subside. ${ }^{3,13}$ Primary repair of late-presenting wounds to achieve a less noticeable scar, carries increased risk for infection. This approach has been substantiated by studies suggesting that primary closure of facial human bites can be undertaken with an acceptable risk within 48 hours and even as late as the fourth day after the injury. ${ }^{3,14,15}$ However, these studies included mainly low-risk wounds (i.e. avulsion type rather than punctures or crush injuries), most of them located on the lips, which are very resistant to the development of infection. Avulsion bite wounds can pose reconstructive challenges if direct closure is not possible. Attempts to reattach avulsed parts are usually doomed to fail. In these cases, local skin flaps or composite grafts should be considered, depending on 
the area involved. Only one patient had presented to us after the 'golden 24-hour period' and was treated with primary closure of the wound. This patient showed no remarkable complications following the treatment. However, we feel the need to include a larger sample size to assess the usefulness of primary closure in such patients.

Antibiotic administration for bite wounds can be either prophylactic or therapeutic., ${ }^{3,16,17}$ In the presence of established infection or any underlying predisposing condition, antibiotic therapy is indicated. However, it remains unclear whether healthy patients with fresh clinically uninfected wounds benefit from prophylactic antibiotic administration. ${ }^{3,17,18}$ Even in these cases, however, antibiotic therapy may actually be therapeutic if enough time has elapsed for bacterial proliferation to reach a level that can result in the development of infection. We followed a protocol where all the patients had been treated with a course of amoxicillin. In cases of contaminated and punctured wounds metronidazole had been added as well. The antibiotic dosages for pediatric patients had been prescribed based on the Clark's formula. None of our patients had reported with allergies to these drugs.

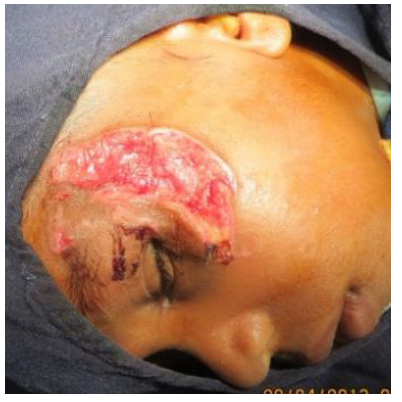

Figure 3a

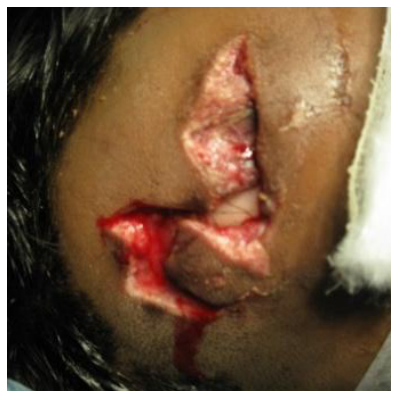

Figure $4 \mathrm{a}$

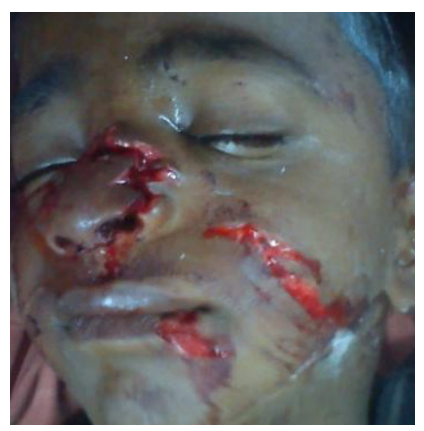

Figure 5a

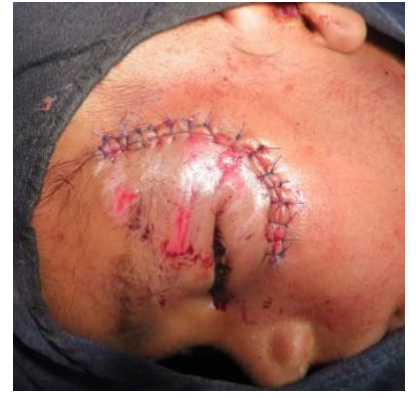

Figure $3 b$

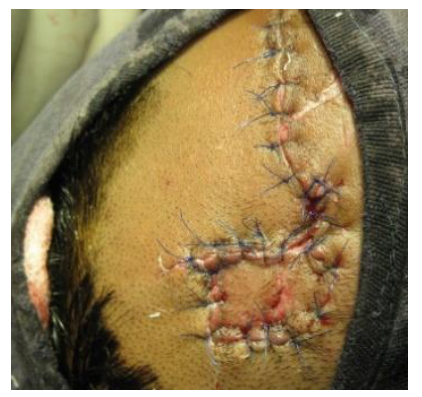

Figure $4 b$

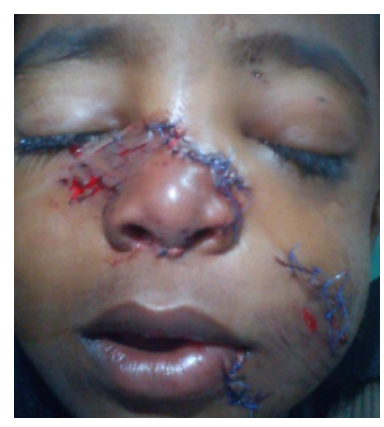

Figure $5 b$

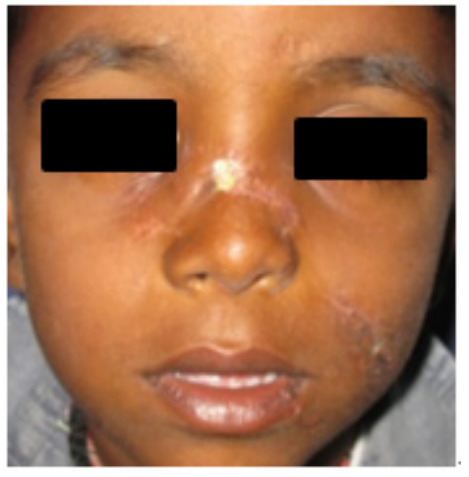

Figure 5c

Figures depicting some of the patients who had been treated with primary closure following dog bite injuries. Fig $3 \mathrm{a}, 3 \mathrm{~b}$ - Class IIA wound over the left temple and its primary closure with local advancement flap. Fig $4 \mathrm{a}, 4 \mathrm{~b}$ - Class IIB wound over the scalp and its primary closure . Fig 5a, 5bmultiple Class I, IIA injuries over the face and the primary closure. Fig $5 \mathrm{c}-$ Minor postoperative scarring

A meta-analysis of prophylactic antibiotics for dog-bite wounds conducted by Callaham ${ }^{8}$ concluded that antibiotics are essential to prevent infections. In a study by Stierman ${ }^{19}$ mainly dealing with high-risk avulsion injuries of the ear, failure to receive at least 48 hours of prophylactic intravenous antibiotics was associated with an increased infection risk following primary closure. It has been suggested that primary closure may also increase the risk of infection, thus further justifying prophylactic antibiotics.

According to current recommendations, amoxicillin/clavulanate is the antimicrobial agent of choice for prophylaxis of bite wounds as it remains active against most animal and human bite wound isolates. ${ }^{3,20,21,22,23,17,24}$ Few clinical trials have examined the use of amoxicillin/clavulanate in bite wounds and reports have appeared noting the failure of amoxicillin/clavulanate in some relevant situations. However, in the series of Kesting and Colleagues ${ }^{16}$, none of the patients who received amoxicillin/clavulanate developed infection, and others have also reported good results with this regimen. The typical course for antibiotic prophylaxis is 3 to 5 days. ${ }^{3,25,26}$ The duration of therapeutic antibiotics varies, depending on the severity of the infection.

Leaving open dog-bite lacerations even secondary closure is unsatisfactory to both the doctor and the patient alike. Primary closure not only minimizes the post-operative scarring but also reduces infection rate. ${ }^{8}$ Debridement is designed to make contaminated wound into clean wound, so that it can be sutured immediately and reach primary healing. Because if the wound is left open, it would get secondary healing and the wound would experience inflammation-hyperplasia of granulation tissue formation. The healing time will be extended and the function would not recover completely due to scar hyperplasia or contracture. ${ }^{2,27}$ Secondary healing results in unacceptable scarring. ${ }^{27}$ Poly propylene, a synthetic, non-absorbable, monofilament suture made by catalytic polymerization of propylene, has low 
tissue reactivity and high tensile strength, similar to nylon. Polypropylene has an extremely smooth surface, which decreases knot security and must be compensated for with extra throws. As significant advantage of prolene is its high plasticity, and ability to accommodate wound edema. Polypropylene is easy to remove. ${ }^{28}$ Due to its low tissue reactivity inflammation of the tissues is kept to minimal. Since, it is monofilament bacterial accumulation is reduced thus reducing the infection rate. All these factors encourage healing and minimize the scar.

Another important aspect of treatment in animal bite wounds is the possibility of Rabies. Rabies is primarily a disease of terrestrial and airborne mammals, including dogs, wolves, foxes, coyotes, jackals, cats, lions, bats and humans. The dogs however have been the main reservoir of rabies in India. Rabies is the 10th biggest cause of death due to infectious diseases worldwide. The annual death toll is around $50000-60000$, with $99 \%$ occurring in tropical developing countries. ${ }^{29}$ While rabies is a $100 \%$ preventable disease, the lack of prophylaxis makes it a $100 \%$ fatal. Based on available evidence, a fair estimate of rabies burden in India is 2.74 rabies cases per 100000 people annually. ${ }^{29}$

We had, in our case series provided anti rabies immunoglobulins and anti-rabies immunization to all the patients as per WHO protocols. None of our patients had presented with symptoms of rabies during our follow up period.

\section{Conclusions}

Dog bite injuries can scar not only the body but also the psyche of the individual. Associated facial scarring can leave a lasting psychological impression in these individuals. Other associated complications such as rabies and septicemia may even be life threatening. The treatment plan must be aimed at achieving optimal esthetics as well as eliminating the possibilities of other complications.

We hence conclude that a thorough wound lavage and primary closure for non-infected wounds under appropriate ant-rabies immunoglobulins for post exposure prophylaxis and antibiotic regimen provides the best results for victims of dog bite injuries to the face.

\section{Acknowledgments}

We would like to thank Dr.Madan Nanjappa HOD, Dr.RajKumar.G.C, Dr.Keerthi.R, Dr.Ashwin.D.P, Dr.Rudresh.K.B, Dr.Prashanth.R, Dr.Vaibhav N and the post graduate students of the department of oral and maxillofacial surgery for their constant support and encouragement.

\section{REFERENCES}

[1] M.KSudarshan . "Assessing burden of rabies in india : WHO sponsored national multicenter rabies survey". IJCM 2005,30(3). E-article (http://www.ijcm.org.in on Monday, August 18, 2014, IP: 14.96.105.160)

[2] Maimaris C, Quinton DN. Dog-bite lacerations: a controlled trial of primary wound closure. Arch Emerg Med 1988;5:156-61.

[3] Panagiotis K. Stefanopoulos.Management of Facial BiteWounds. Oral Maxillofacial Surg Clin N Am 21 (2009) 247-257.

[4] Lackmann GM, Isselstein G, Tollner U, Draf W. Facial injuries caused by dog bites in childhood. Clinical staging, therapy and prevention. Monatsschr Kinderheilkd. 1990 Nov;138(11):742-8.

[5] Lackmann GM, DrafW, Isselstein G, et al. Surgical treatment of facial dog bite injuries in children. J Craniomaxillofac Surg 1992;20:85.

[6] Brook I. Management of human and animal bite wounds: an overview. Adv Skin Wound Care 2005;18:197-203.

[7] Abubaker AO. Management of posttraumatic soft tissue infections. Oral Maxillofac Surg Clin NorthAm 2003;15:139-46

[8] Callaham M. Prophylactic antibiotics in dog bite wounds: nipping at the heels of progress. Ann Emerg Med 1994;23:577-9.

[9] Hollander JE, Singer AJ. Laceration management Ann Emerg Med 1999;34:356-67.

[10] Hallock GG. Dog bites of the face with tissue loss. J Craniomaxillofac Trauma 1996;2:49-55.

[11] Lieblich SE, Topazian RG. Infection in the patient with maxillofacial trauma. In: Fonseca RJ,Walker RV, Betts NJ, et al, editors. Oral and maxillofacial trauma. 3rd edition. St Louis (MO): Elsevier Saunders; 2005. p. 1109-30.

[12] Simon B, Hern HG Jr. Wound management principles. In: Marx JA, editor. Rosen's emergency medicine: concepts and clinical practice. 6th edition. Philadelphia: Mosby Elsevier; 2006. p. 842-57.

[13] Dimick AR. Delayed wound closure: indications and techniques. Ann Emerg Med 1988;17:1303-4.

[14] Venter THJ. Human bites of the face. S Afr Med J 1988;74:277-9.

[15] Donkor P, Bankas DO. A study of primary closure of human bite injuries to the face. J Oral Maxillofac Surg 1997;55:47981 .

[16] Kesting MR, Ho“ lzle F, Pox C, et al. Animal bite injuries to the head: 132 cases. Br J Oral Maxillofac Surg 2006;44:2359.

[17] Nakamura Y, Daya M. Use of appropriate antimicrobials in wound management. Emerg Med Clin North Am 2007;25:159-76.

[18] Kountakis SE, Chamblee SA, Maillard AAJ, et al. Animal bites to the head and neck. Ear Nose Throat J 1998;77:21620. 
[19] Stierman KL, Lloyd KM, De Luca-Pytell D, et al. Treatment and outcome of human bites in the head and neck. Otolaryngol Head Neck Surg 2003;128:795-801.

[20] Javaid M, Feldberg L, Gipson M. Primary repair of dog bites to the face: 40 cases. J R Soc Med 1998;91:414-6 B.

[21] Goldstein EJC. Outpatient management of dog and cat bite wounds. Family Practice Recertification 2000;22:67-86.

[22] Moran GJ, Talan DA, Abrahamian FM. Antimicrobial prophylaxis for wounds and procedures in the emergency department. Infect Dis Clin North Am 2008;22:117-43.

[23] Chaudhry MA, MacNamara AF, Clark S. Is the management of dog bite wounds evidence based? A postal survey and review of the literature. Eur J Emerg Med 2004;11:313-7.

[24] Gilbert DN, Moellering RC Jr, Eliopoulos GM, et al.The Sanford guide to antimicrobial therapy 2007.

[25] Goldstein EJC. Bite wounds and infection. Clin Infect Dis 1992;14:633-40.

[26] Stevens DL, Bisno AL, Chambers HF, et al. Practice guidelines for the diagnosis and management of skin and soft-tissue infections. Clin Infect Dis 2005;41:1373-406.

[27] Ri-feng etal. Emergency treatment of facial laceration of dog bite wounds with immediate primary closure: A prospective randomized trail study. BMC Emergency Medicine 2013;13(suppl 1):s2
[28] Hochberg J, Meyer MK, Marion MD. Suture choice and other methods of skin closure. Surg Clin N Am 2009;89:627-641

[29] Baxter.J.M. One in a million, or one in thousand: What is the morbidity of rabies in India?JOGH 2012,2(1). E-article(www.jogh.org • doi: 10.7189/jogh.02.010303)

[30] Dire DJ,Hogn DE,Walker JS. Prophylactic oral antibiotics for low risk dog bite wounds. Ped emerg care 1992,8: 194-97.

[31] Maral Fathalla Thabit, Rawah Adnan Faraj. Epidemiological study of dog bite cases in Baghdad city during 2010. Al Qadisial Medical Journal 2011;7(11):1-7.

[32] Marr JS, Beck AM, Lugo JA. An epidemiologic study of the human bite. Public Health Rep 1979; 94:514-21.

[33] Javaid M, Feldberg L, Gipson M. Primary repair of dog bites to the face: 40 cases. J R Soc Med 1998;91:414-416.

[34] Natarajan S, Galinde JS, Asnani U, Sidana S, Ramaswami R. Facial Dog Bite Injury. J Contemp Dent 2012;(2):34-38.

[35] Mohd Junaid et al. Epidemiological study of dog bite victims in anti rabies. clinic of a tertiary care hospital. IJBHS 2012; 1(1):12-16.

[36] National guidelines for management of animal bites. E article (http://rabies.org.in/rabies-journal/rabies-07/guidelines.htm)

[37] Abuabara A. A review of facial injuries due to dog bites. Med Oral Patol Oral Cir Bual 2006;11:348-350 